\title{
Pengaruh Penggunaan Limbah Kantong Plastik Sebagai Bahan Tambah dalam Campuran Ac - Base
}

\author{
Dody Pagewang*1, Rais Rachman ${ }^{* 2}$, Alpius ${ }^{\star 3}$ \\ *1 Mahasiswa Program Studi Teknik Sipil, Universitas Kristen Indonesia Paulus, Makassar, Indonesia \\ Dodypagewang97@gmail.com \\ *2,3 Dosen Program Studi Teknik Sipil, Universitas Kristen Indonesia Paulus, Makassar, Indonesia
}

\begin{abstract}
ABSTRAK
Penelitian ini dimaksudkan untuk mengetahui pengaruh penggunaan limbah kantong plastic sebagai bahan tambah dalam campuran Ac-Base. Metode dalam penelitian ini adalah melakukan serangkaian pengujian karakteristik agregat kasar, halus, filler dan aspal kemudian merancang komposisi campuran AC-BASE serta pengujian Marshall untuk mendapatkan karakteristik campuran dengan pengujian Marshall Immersion untuk memperoleh indeks kekuatan sisa (IKS) dengan menggunakan kadar aspal optimum. Hasil penelitian yang dilakukan di laboratorium Jalan dan Aspal Fakultas Teknik Jurusan Sipil Universitas Kristen Indonesia Paulus Makassar, menunjukkan bahwa karakteristik bahan perkerasan berupa agregat dari Sungai Jeneberang yang di tambahkan dengan limbah kantong plastik memenuhi Spesifikasi Umum Bina Marga 2018 sebagai bahan lapisan perkerasan jalan. Melalui uji Marshall diperoleh karakteristik campuran AC-BASE dengan kadar plastik 0.00\%, 0.50, 1.00\%, 1.50\%, 2.00\%. Hasil pengujian Marshall Immersion campuran AC-BASE dengan kadar plastik optimum 2.00\% diperoleh Indeks Kekuatan Sisa (IKS) sebesar 98,31\% yang memenuhi Spesifikasi Umum Bina Marga 2018 yaitu 90\%.
\end{abstract}

Kata Kunci: Karakteristik Agregat, Campuran AC-BASE, Marshall test

\begin{abstract}
This study was intended to determine the effect of using plastic bag waste as an added ingredient in the Ac-Base mixture. The method in this research is to conduct a series of testing the characteristics of coarse, fine aggregate, filler and asphalt then design the composition of the AC-BASE mixture and Marshall test to obtain the mixture characteristics by Marshall Immersion testing to obtain the remaining strength index (IKS) using optimum asphalt content. The results of research conducted at the Road and Asphalt Laboratory of the Faculty of Civil Engineering, Indonesian Christian University, Paulus Makassar, showed that the characteristics of pavement materials in the form of aggregates from the Jeneberang River which were added with plastic bag waste met 2018 Highways Quality Specifications as road pavement coating materials. Through the Marshall test obtained the characteristics of AC-BASE mixture with plastic content $0.00 \%$, $0.50,1.00 \%, 1.50 \%, 2.00 \%$. The results of the Marshall Immersion test of AC-BASE mixture with an optimum plastic content of $2.00 \%$ obtained a Residual Strength Index (IKS) of $98.31 \%$ which met the General Specifications of the 2018 Highways which is $90 \%$.
\end{abstract}

Keywords: Agregate Characteristics, AC-BASE Mixture, Marshall test

\section{PENDAHULUAN}

Di Indonesia kondisi suatu jalan sangat perlu di perhatikan, karena jalan merupakan salah satu sarana perhubungan yang sangat penting bagi sektor ekonomi dan sosial. Seiring dengan meningkatnya status sosial masyarakat, maka kecenderungan meningkatnya jumlah kendaraan secara global melewati suatu jalan. Pada saat menggunakan jalan, tuntutan pengguna jalan adalah kenyamanan, keselamatan dan kecepatan.
Untuk memperbaiki mutu perkerasan, saat ini ada bermacam-macam bahan tambah, salah satunya adalah limbah kantong plastik yang dapat ditambahkan kedalam campuran beraspal. Dengan penambahan limbah kantong plastik kedalam aspal diharapkan dapat memberikan daya tahan aspal terhadap suhu tinggi dan dapat meningkatkan daya lekat aspal terhadap agregat sehingga air akan susah meresap kedalam lapisan perkerasan jalan [1]. Salah satu penyebab rusaknya jalan adalah air karena meresap 
kedalam badan jalan dan menyebabkan daya lekat aspal menjadi berkurang [2].

Dalam penelitian ini, bahan tambah limbah kantong plastik digunakan pada campuran $A C$ $B A S E$. Lapisan $A C$-BASE ini berfungsi untuk memberi dukungan lapis permukaan, mengurangi regangan dan tegangan, menyebarkan dan meneruskan beban konstruksi jalan di bawahnya.

Perkerasan jalan merupakan lapisan konstruksi yang telah mengalami proses pemadatan yang terletak diatas tanah dasar (subgrade) dan berfungsi untuk memikul beban lalu lintas yang kemudian menyebarkannya kebadan jalan sehingga tanah dasar bisa menerima beban sesuai daya dukung tanah yang diijinkan. Tujuan dari pembuatan lapis perkerasan jalan adalah agar dicapai suatu kekuatan tertentu sehingga mampu mendukung beban lalu lintas dan dapat menyalurkan serta menyebarkan beban roda-roda kendaraaan ke tanah dasar.

Stabilitas adalah kemampuan lapisan perkerasan menerima beban lalu-lintas tanpa mengalami perubahan bentuk tetap (deformasi permanen) seperti gelombang, alur (rutting), maupun mengalami bleeding.

Kelelehan adalah deformasi vertikal yang terjadi mulai awal pembebanan sampai kodisi stabilitas menurun, yang menunjukkann besarnya deformasi yang terjadi pada lapisan perkerasan akibat menahan beban yang diterimanya.

Rongga di dalam Campuran (VIM) dalam campuran perkerasan jalan terdiri atas ruangan udara diantara agregat yang terselimuti aspal.

Rongga didalam Agregat (VMA) adalah ruang diantara partikel agregat pada suatu perkerasan beraspal, termasuk rongga udara dan volume aspal efektif (tidak termasuk volume aspal yang diserap agregat).

VFB (Rongga terisi aspal) adalah persen rongga yang terdapat diantara partikel agregat yang terisi oleh aspal (tidak termasuk aspal yang diserap oleh agregat).

Marshall Quotient, nilai MQ menyatakan sifat kekuatan suatu campuran. Bila nilai $M Q$ terlalu tinggi, maka campuran akan cenderung terlalu kaku dan mudah retak. Sebaliknya bila nilai $\mathrm{MQ}$ terlalu rendah, maka perkerasan menjadi lentur dan cenderung kurang stabil.

Indeks Kekuatan Sisa adalah perbandingan antara stabilitas benda uji selama perendaman dan stabilitas benda uji standar dinyatakan dalam persen. IKS digunakan untuk menentukan kepekaan kekuatan beton aspal yang dinyatakan dengan nilai stabilitas akibat penurunan kekuatan benda uji akibat kerusakan oleh air.
Beberapa penelitian yang meneliti tentang campuran AC-Base antara lain :

Yudi at.al (2019) meneliti Karakteristik Campuran AC-WC dan AC-BC Menggunakan Bahan Tambah Serat ljuk [3]. Irpan et.al (2020) meneliti tentang Pemanfaatan Batu Gunung Ambeso pada Campuran AC-Base [4]. Fitri e.al. (2018) meneliti tentang pengaruh penambahan limbah plastik kresek sebagai substitusi aspal pen 60/70 terhadap karakteristik campuran Laston AC-BC [5]. Bunga at.al (2019) meneliti tentang Effect of Collision Variation towards the Index Retained Strength of Mixed Asphalt Concrete Wearing Course [6]. Sumardi at.al (2019) meneliti tentang Study of the Use Bagasse Ash as a Filler Replacement to Characteristics Asphalt Concrete [7]. Datu at.al (2020) menelti tentang The Effect of Additional Sugar Palm Fibers on the Durability of Mixed Laston AC-WC [8]. Rachman (2019) meneliti tentang Pemanfaatan Batu Gunung Bottomale Toraja Utara sebagai Campuran Laston [9]. Selain itu beberapa peneliti yang meneliti bahan limbah sebagai campuran Laston antara lain: Daud at.al meneliti tentang Study of HRS-WC Mixture Performance Using the Waste of Crude Palm Oil Ash as Filler [10].

Tujuan penelitian yaitu untuk mengetahui pengaruh penambahan limbah kantong plastik terhadap pengujian Marshall Konvensional. untuk mengetahui pengaruh penambahan limbah kantong plastik terhadap pengujian Marshall immersion.

\section{METODOLOGI PENELITIAN}

\section{Lokasi dan Waktu Penelitian}

Lokasi penelitian adalah laboratorium aspal UKI Paulus Makassar .

\section{Metode Pengujian}

Campuran beraspal menggunakan 3 (tiga) bahan utama yaitu agregat, aspal, dan filler. Untuk memenuhi karakteristik campuran beraspal, maka rancangan campran harus mengikuti spesifikasi Umum Bina Marga 2018. Yang utama dalam rancangan campuran adalah gradasi dari campuran itu sendiri,sehingga untuk mendapatkan karakteristik campuran yang baik maka gradasi yang digunakan yaitu gradasi ideal dengan mengambil nilai tengah dari batasan gradasi (batas atas dan bawah gradasi/ rata-rata batas gradasi).Pemeriksaan Marshall Konvensional.

\section{Pemeriksaan Karakteristik Bahan}

Perancangan dan pengujian karakteristik campuran beraspal harus mengikuti standar/spesifikasi yang ada. Untuk Indonesia, standar/spesifikasi yang digunakan adalah spesifikasi Umum Bina Marga 2018. 
Rancangan pengujian didahului pengujian karakteristik bahan. Jika hasil pengujian tidak sesuai spesifikasi (berat jenis, keausan dan kelekatan) maka agregat tidak boleh digunakan juga jika karakteristik campuran tidak memenuhi spesifikasi maka campuran tersebut tidak boleh di produksi ( kecuali dilakukan modifikasi dengan bahan tambah) jika memenuhi spesifikasi maka dilanjutkan dengan rancangan campuran.

\section{a. Karakteristik agregat}

Standar rujukan/acuan pemeriksaan Analisa saringan agregat kasar dan agregat halus mengacu pada metode atau standar SNI ASTM C136:2012. Pemeriksaan berat jenis dan penyerapan agregat kasar mengacu pada standar rujukan SNI 1969:2016 dan Pemeriksaan berat jenis dan penyerapan air agregat halus mengacu pada standar rujukan SNI 1970:2016. Standar rujukan/acuan pemeriksaan kadar lumpur dan SE (Sand Equivalent) mengacu pada standar rujukan SNI 03-4428-1997. Pengujian Keausan (Abration) ini mengacu pada standar rujukan SNI 24172008. Pemeriksaan partikel kepipihan dan kelonjongan mengacu pada standar rujukan ASTM D - 4791-10 dengan perbandingan 1:5. Pemeriksaan agregat lolos ayakan No. 200 mengacu pada standar rujukan SNI ASTM C117:2012.

\section{b. Karakteristik Aspal}

Pengujian Penetrasi pada $25^{\circ} \mathrm{C}$ merujuk pada SNI 2456:2011; Pengujian Titik Nyala merujuk SNI 2433:2011; Pengujian Titik Lembek $\left({ }^{\circ} \mathrm{C}\right)$ SNI2434;2011; Pengujian Berat Jenis SNI 2441:2011; Pengujian Daktilitas pada $25^{\circ} \mathrm{C}$ SNI 2432:2011; Pengujian Berat yang Hilang (\%) menggunakan SNI-06-2441-1991.

\section{c. Komposisi Campuran}

Campuran beraspal menggunakan 3 (tiga) bahan utama yaitu agregat, aspal, dan filler. Untuk memenuhi karakteristik campuran beraspal, maka rancangan campran harus mengikuti spesifikasi Umum Bina Marga 2018.

Pengujian terhadap sifat benda uji (stabilitas dan flow) ini dibagi dalam 2 kelompok yaitu perendaman standar (30 menit) pada suhu $60^{\circ} \mathrm{C}$ dan selama waktu yang diperlukan.

\section{a. Analisis KAO}

Kadar Aspal Optimum merupaka persyaratan dalam standar spesifikasi yang dikeluarkan oleh Bina Marga

\section{b. Pemeriksaan Marshall Immersion}

Pada penelitian ini dipakai metode uji perendaman (Marshall) selama 24 jam dalam suhu konstan $60^{\circ} \mathrm{C}$ sebelum pembebanan diberikan.
Berdasarkan hasil rancangan komposisi campuran AC-BASE yang menggunakan agregat sungai Jeneberang dan ditambahkan dengan limbah kantong plastik telah memenuhi Spesifikasi Umum Bina Marga 2018, dimana kadar plastik rancangan yang digunakan yaitu $0.00 \%, 0.50 \%, 1.00 \%, 1.50 \%, 2.00 \%$.

Tabel 1. Rancangan komposisi campuran ACBASE

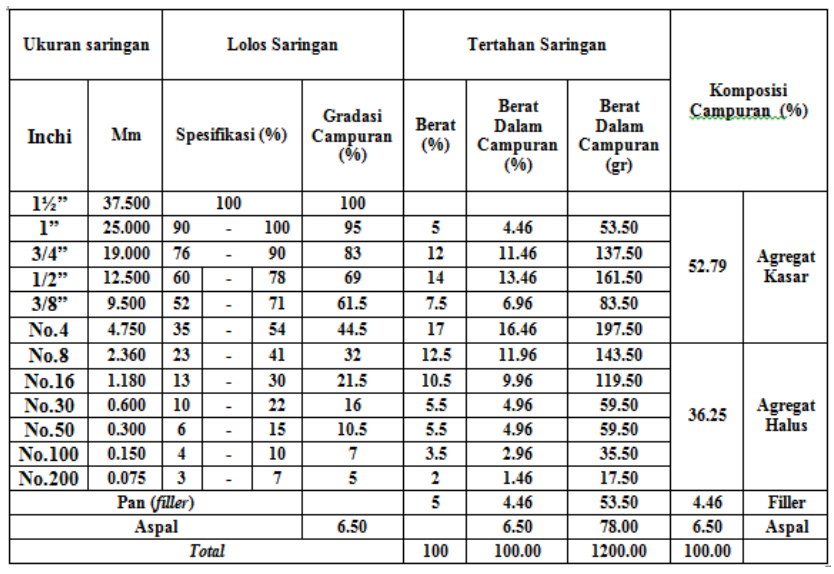

\section{Teknik Analisis Data}

Dalam hal ini pengolahan data-data hasil pengujian dalam bentuk numerik dan akan dianalisis dengan rumus empirik statistikamatematis. Adapun tahapan- tahapan teknik analisis data dijelaskan sebagai berikut:

\section{a. Analisis Karakteristik Agregat}

Pada tahap ini dilakukan analisis karakteristik agregat dengan standar spesifikasi Bina Marga.

b. Analisis Regresi

Pada tahap ini dilakukan analisis regresi hubungan antara variabel yang menjadi karakteristik campuran.

\section{ANALISIS DAN PEMBAHASAN}

\section{Hubungan Kadar Plastik Terhadap VIM}

Persamaan regresi persamaan garis $y=$ $0,0,0314 x^{2}-0,1435 x+3,5312$ menunjukan setiap kenaikan $0,50 \%$ kadar plastik, maka VIM semakin menurun. Dari hasil persamaan regresi menunjukkan bahwa nilai VIM mencapai batas minimum yaitu $3 \%$ pada kadar aspal $2,42 \%$. Nilai VIM berdasarkan persamaan regresi dapat dilihat pada Tabel 3 dan Pengujian VIM campuran AcBase disajikan pada Tabel 2 dan Gambar 1. 
http://ojs.ukipaulus.ac.id/index.php/pcej

Tabel 2. Kadar plastik dan nilai VIM

\begin{tabular}{|c|c|c|c|c|c|}
\hline $\begin{array}{c}\text { Kadar Plastik } \\
(\%)\end{array}$ & 0.00 & 0.50 & 1.00 & 1.50 & 2.00 \\
\hline \multirow{2}{*}{ VIM } & 3.52 & 3.44 & 3.35 & 3.23 & 3.10 \\
\cline { 2 - 6 } & 3.50 & 3.46 & 3.33 & 3.29 & 3.12 \\
\cline { 2 - 6 } & 3.56 & 3.48 & 3.37 & 3.21 & 3.14 \\
\hline Rata-Rata & 3.53 & 3.46 & 3.35 & 3.24 & 3.12 \\
\hline Persyaratan & \multicolumn{5}{|c|}{$3-5 \%$} \\
\hline
\end{tabular}

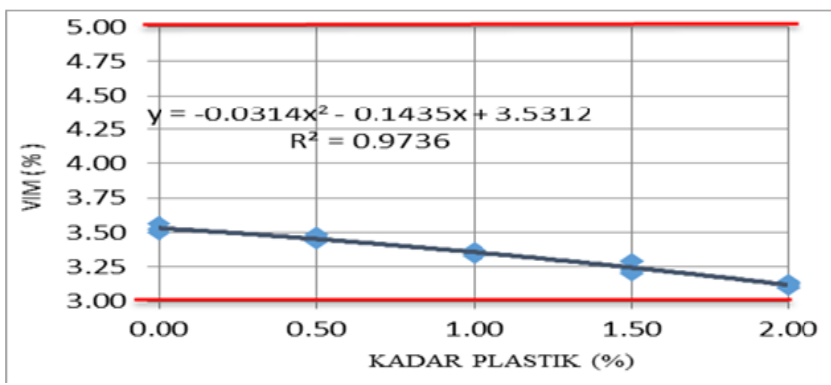

Gambar 1. Hubungan kadar plastik dan VIM

\section{Hubungan Kadar Plastik Terhadap Stabilitas}

Dari hasil regresi hubungan kadar plastic terhadap stabilitas diperoleh persamaan garis $\mathrm{y}=$ $-22,2871 x^{2}+272,16 x-1822,8$ di peroleh bahwa setiap kenaikan $0,50 \%$ kadar plastik, maka stabilitas bertambah. Dari hasil perhitungan persamaan Regresi menunjukkan bahwa Stabilitas maksimum berada pada kadar plastik $5,95 \%$ dengan nilai stabilitas sebesar $2632,46 \mathrm{~kg}$. Nilai stabilitas berdasarkan persamaan regresi dan pengujian stabilitas, masing-masing disajikan pada Tabel 3 dan Gambar 2.

Tabel 3. Pengujian stabilitas campuran AC-

\section{BASE}

\begin{tabular}{|c|c|c|c|c|c}
\hline $\begin{array}{c}\text { Kadar } \\
\text { Aspal }\end{array}$ & 0.00 & 0.50 & 1.00 & 1.50 & 2.00 \\
\hline \multirow{3}{*}{ Stabilitas } & 1852.54 & 1886.85 & 2081.25 & 2229.91 & 2252.78 \\
\cline { 2 - 6 } & 1841.11 & 1875.41 & 2092.69 & 2218.48 & 2241.35 \\
\cline { 2 - 6 } & 1863.98 & 1898.29 & 2104.12 & 2207.04 & 2264.22 \\
\hline Rata-rata & 1852.54 & 1886.85 & 2092.69 & 2218.48 & 2252.78 \\
\hline Persyaratan & \multicolumn{5}{|c|}{ Min 1800} \\
\hline
\end{tabular}

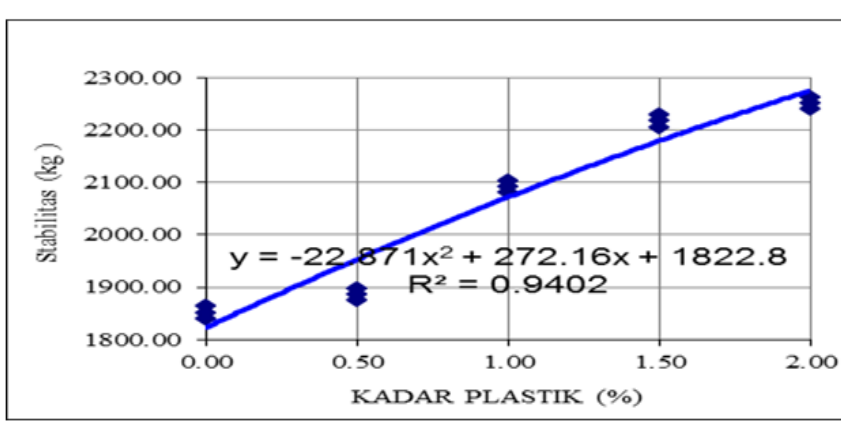

Gambar 2. Hubungan kadar plastik terhadap stabilitas

\section{Hubungan Kadar Plastik Terhadap VMA}

Dari regresi hubungan kadar plastic terhadap VMA menghasilkan persamaan garis $y=-0,027 x^{2}$ $-0,123 x+17,287$ menunjukan setiap kenaikan $0,50 \%$ kadar plastik, maka VMA semakin menurun. Hasil perhitungan persamaan Regresi menunjukkan bahwa VMA mencapai batas minimum yaitu $15 \%$ pada kadar $7,2 \%$.

Tabel 4. Pengujian VMA pada campuran ACBASE

\begin{tabular}{|c|c|c|c|c|c|}
\hline $\begin{array}{c}\text { Kadar } \\
\text { Plastik }\end{array}$ & 0.00 & 0.50 & 1.00 & 1.50 & 2.00 \\
\hline \multirow{3}{*}{ VMA } & 17.28 & 17.21 & 17.13 & 17.03 & 16.92 \\
\cline { 2 - 6 } & 17.26 & 17.23 & 17.12 & 17.08 & 16.94 \\
\cline { 2 - 6 } & 17.31 & 17.24 & 17.15 & 17.01 & 16.95 \\
\hline Rata-rata & 17.28 & 17.23 & 17.13 & 17.04 & 16.94 \\
\hline Persyaratan & \multicolumn{5}{|c|}{ Min 15 } \\
\cline { 2 - 5 } & \multicolumn{5}{|c|}{} \\
\hline
\end{tabular}

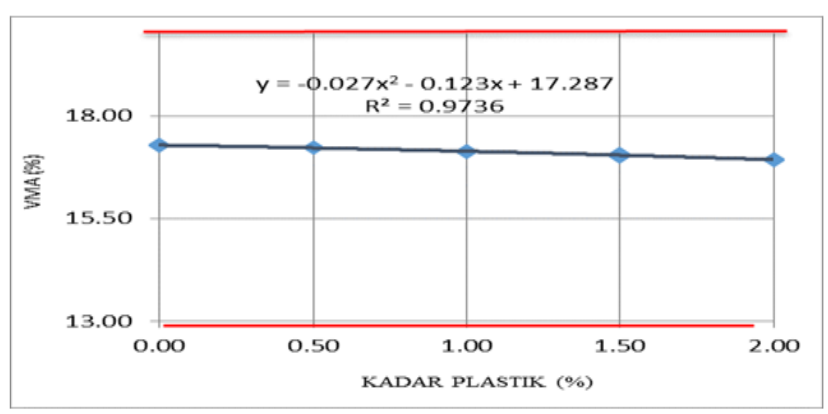

Gambar 3. Hubungan kadar aspal dan VMA

\section{Hubungan Kadar Aspal Terhadap Flow}

Nilai Flow minimum berada pada kadar plastik $2,57 \%$ dengan nilai $3 \mathrm{~mm}$. Gambar 5 menunjukkan persamaan garis $y=0,0857 x^{2}-$ $0,1286 x+3,8971$ menunjukan bahwa setiap kenaikan $0,50 \%$ kadar plastik, maka Flow akan semakin menurun.

Tabel 5. Pengujian flow campuran AC-BASE

\begin{tabular}{|c|c|c|c|c|c|}
\hline $\begin{array}{c}\text { Kadar } \\
\text { Aspal }\end{array}$ & 0.00 & 0.50 & 1.00 & 1.50 & 2.00 \\
\hline \multirow{3}{*}{ Flow } & 3.90 & 3.80 & 3.70 & 3.60 & 3.30 \\
\cline { 2 - 6 } & 3.80 & 3.90 & 3.60 & 3.50 & 3.35 \\
\cline { 2 - 6 } & 4.00 & 3.70 & 3.80 & 3.40 & 3.25 \\
\hline Rata-rata & 3.90 & 3.80 & 3.70 & 3.50 & 3.30 \\
\hline Persyaratan & \multicolumn{5}{|c}{$3-6(\mathrm{~mm})$} \\
\end{tabular}




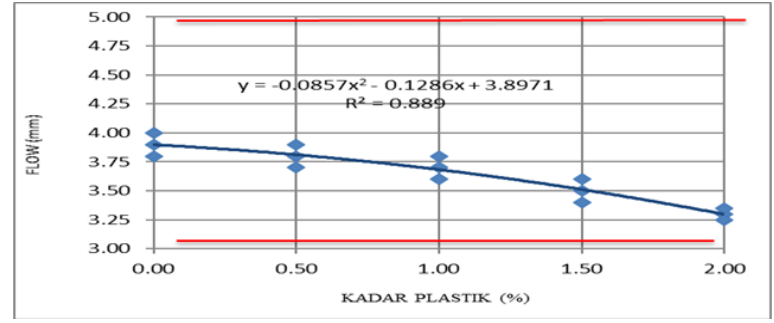

Gambar 4. Hubungan kadar plastik dan flow

\section{Hubungan Kadar Aspal Terhadap VFB}

Dari hubungan VFB dan kadar plastik secara regresi, diperoleh persamaan garis $\mathrm{y}=$ $0,1628 x^{2}+0,6791 x+79,574$ menunjukkan bahwa setiap kenaikan $0,5 \%$ kadar plastik, maka VFB semakin meningkat.

Tabel 6. Pengujian VFB campuran AC-BASE

\begin{tabular}{|c|c|c|c|c|c}
\hline $\begin{array}{c}\text { Kadar } \\
\text { Plastik (\%) }\end{array}$ & 0.00 & 0.50 & 1.00 & 1.50 & 2.00 \\
\hline \multirow{3}{*}{ VFB } & 79.62 & 80.02 & 80.43 & 81.05 & 81.68 \\
\cline { 2 - 6 } & 79.72 & 79.92 & 80.53 & 80.74 & 81.57 \\
\cline { 2 - 6 } & 79.43 & 79.82 & 80.33 & 81.15 & 81.46 \\
\hline Rata-rata & 79.59 & 79.92 & 80.43 & 80.98 & 81.57 \\
\hline Persyaratan & \multicolumn{5}{|c}{ Min 65 } \\
\hline
\end{tabular}

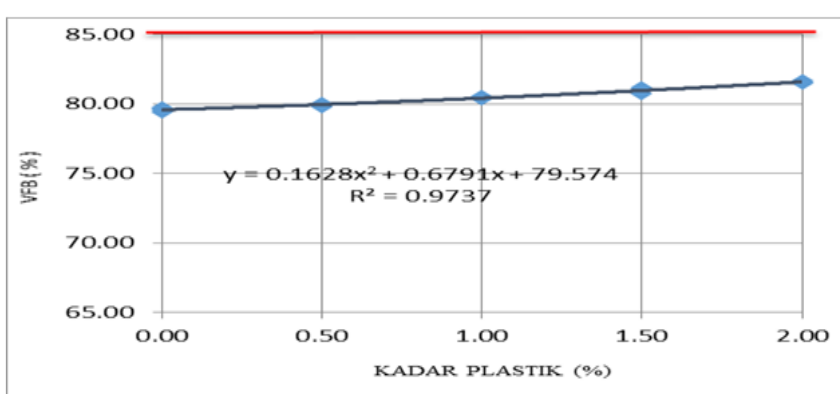

Gambar 5. Hubungan Kadar Plastik dan VFB

\section{Penentuan Kadar Aspal Optimum}

Untuk campuran AC-BASE di pilih yang memiliki nilai stabilitas terbesar yaitu pada kadar aspal $2.00 \%$ karena campuran AC-BASE adalah lapisan yang berfungsi untuk memberi dukungan terhadap lapis permukaan, mengurangi regangan dan tegangan, menyebarkan dan meneruskan beban konstruksi jalan di bawahnya.

\section{Indeks Perendaman / Kekuatan Sisa}

Untuk kadar $2 \%$ nilai indeks kekuatan sisa $97,97 \%$ pada nilai stabilitas konvensional dan immertion, masing-masing 2252,78 dan 2207,04. Sedangkan untuk indeks kekuatan sisa $97,95 \%$ pada nilai stabilitas konvensional 2241,35 dan immertion 2195,61.
Tabel 8. Indeks kekuatan sisa campuran

\begin{tabular}{|c|c|c|c|}
\hline PERSYARATAN & \multicolumn{2}{|c|}{ Stabilitas } & $\begin{array}{c}\text { Indeks Perendaman / } \\
\text { Indeks Kekuatan Sisa } \\
\mathbf{( \% )}\end{array}$ \\
\hline $\begin{array}{c}\text { Kadar Limbah } \\
\text { plastik(\%) }\end{array}$ & Konvensional & Immertion & 97,97 \\
\hline 2 & 2252,78 & 2207,04 & 97,95 \\
\hline 2 & 2241,35 & 2195,61 & 98,99 \\
\hline 2 & 2264,22 & 2241,35 & $\mathbf{9 8 , 3 1}$ \\
\hline Rata-rata & $\mathbf{2 2 5 2 , 7 8}$ & $\mathbf{2 2 1 4 , 6 7}$ & \\
\hline
\end{tabular}

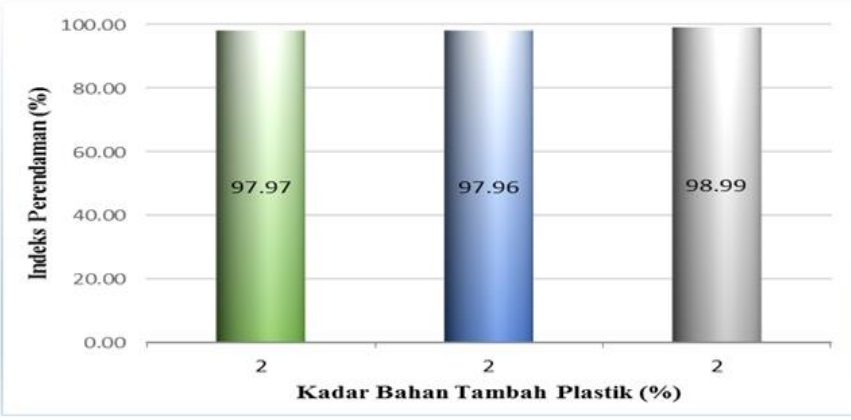

Gambar 6. Indeks kekuatan sisa

\section{Pembahasan}

Jika kadar plastik bertambah banyak lagi maka selimut aspal menjadi lebih tebal yang akan mengakibatkan ikatan antar agregat atau stabilitas campuran kembali menurun.

Penggunaan plastik yang banyak dalam campuran beraspal akan membantu mengisi rongga diantara agregat (dalam campuran).

Jika penggunaan plastik bertambah banyak maka ikatan antar agregat dalam campuran menjadi lebih kuat yang mengakibatkan kelenturan campuran menurun, kemudian jika penggunaan aspal bertambah banyak lagi maka selimut aspal menjadi lebih tebal yang mengakibatkan kekuatan campuran berkurang tetapi kelenturan bertambah besar.

Indeks kekuatan sisa dengan nilai $98,98 \%$ pada nilai stabilitas konvensional dan immertion, masing-masing 2264,22 dan 2241,35. Rata-rata indeks kekuatan sisa $98,31 \%$., artinya campuran tahan terhadap suhu.

\section{KESIMPULAN}

Karakteristik agregat yang berasal dari Sungai Jeneberang Kecamatan Bili-bili Kabupaten Gowa, untuk campuran AC-BASE memenuhi Spesifikasi Umum Bina Marga 2018 yang artinya dapat digunakan sebagai bahan pembangunan jalan khususnya lapisan beraspal (AC-BASE).

Hasil pengujian Marshall Konvensional diperoleh karakteristik beraspal semua memenuhi Spesifikasi yaitu Stabilitas, Flow, VIM, VMA, dan VFB dan hasil uji Marshall Immersion (Indeks Kekuatan Sisa) pada campuran AC-BASE yaitu 
$98,31 \%>90 \%$ yang menggunakan bahan tambah limbah kantong plastik memenuhi Spesifikasi Umum Direktor Jendral Bina Marga 2018.

\section{DAFTAR PUSTAKA}

[1] G. Rusbintardjo, 2013, Aspal- Bahan Perkerasan Jalan, 1st ed. Semarang, Indonesia: UNISSULA Press.

[2] H. Hardiyatmo Christady, 2019, Perancangan Perkerasan Jalan dan Penyelidikan Tanah, Edisi 3. Yogyakarta: Gajah Mada University Press.

[3] Yudi. I, Angga I, Elizabeth, and Alpius, 2019, "Karakteristik Campuran AC-WC dan AC-BC Menggunakan Bahan Tambah Serat ljuk," Paulus Civ. Eng. J. Ojsukipaulusacid, vol. 1, no. 2, Art. no. 2.

[4] Irpan, R. Mangontan, and Alpius, 2020, "Pemanfaatan Batu Gunung Ambeso pada Campuran AC-Base," Paulus Civ. Eng. J. Ojsukipaulusacid, vol. 2, no. 1, pp. $58-62$.

[5] S. S. Fitr, M. Saleh, and M. Isya, 2018, "Pengaruh Penambahan Limbah Plastik Kresek Sebagai Substitusi Aspal Pen 60/70 Terhadap Karakteristik Campuran Laston AC-BC," J. Tek. Sipil, vol. 1, no. 3, pp. 737748, doi: 10.24815/jts.v1i3.10034.
[6] D. N. Bunga, R. Rachman, and $M$. Selintung 2019, "Effect of Collision Variation towards the Index Retained Strength of Mixed Asphalt Concrete Wearing Course," Int. J. Sci. Eng. Sci., vol. 3, no. 8, Art. no. 8, doi: 10.5281/zenodo.3408003.

[7] Sumardi, R. Rachman, and J. Tanijaya, 2019, "Study of the Use Bagasse Ash as a Filler Replacement to Characteristics Asphalt Concrete," Int. J. Sci. Eng. Sci., vol. 3, no. 8, Art. no. 8, doi: 10.5281/zenodo.3408011.

[8] S. A. Datu, R. Rachman, and M. Selintung, 2020, "The Effect of Additional Sugar Palm Fibers on the Durability of Mixed Laston AC-WC," Bali, Indonesia, vol. 419, doi: 10.1088/1755-1315/419/1/012063.

[9] R. Rachman, 2020, "Pemanfaatan Batu Gunung Bottomale Toraja Utara sebagai Campuran Laston," J. Tek. Sipil Dan Teknol., vol. 6, no. 1, Art. no. 1.

[10] Daud, R. Rachman, and J. Tanijaya, 2020, "Study of HRS-WC Mixture Performance Using the Waste of Crude Palm Oil Ash as Filler," Bali, Indonesia, vol. 419, doi: 10.1088/1755-1315/419/1/012101. 